\title{
INFLUÊnCIA DA DISTRIBUIÇÃo EsPaCIAL Do MILHO E DA Brachiaria brizantha Consorciados sobre a PopulaçÃo de Plantas Daninhas em Sistema Plantio Direto na Palha ${ }^{1}$
}

\author{
Influence of the Spatial Distribution of Maize and Brachiaria brizantha Intercropping on the \\ Weed Population Under No-Tillage
}

BORGHI, E. ${ }^{2}$, COSTA, N.V. ${ }^{2}$, CRUSCIOL, C.A.C. ${ }^{3}$ e MATEUS, G.P. ${ }^{4}$

\begin{abstract}
RESUMO - O cultivo consorciado de milho com forrageiras tropicais no sistema plantio direto na palha pode diminuir a incidência de plantas daninhas em decorrência da elevada produção de fitomassa e da alelopatia proporcionada pela deposição superficial de palha no solo. Este trabalho objetivou avaliar a influência da distribuição espacial da cultura do milho com Brachiaria brizantha, cultivados em consórcio no sistema plantio direto na palha, sobre a população de plantas daninhas. O experimento foi instalado em condições de campo, nos anos agrícolas 2002/03 e 2003/04, na Fazenda Experimental Lageado, em Botucatu-SP. O delineamento experimental foi o de blocos casualizados em esquema fatorial simples $2 \times 4$, com quatro repetições. Os tratamentos foram dois espaçamentos entre linhas de milho $\left(\mathrm{E}_{1}-45 \mathrm{~cm}\right.$ e $\left.\mathrm{E}_{2}-90 \mathrm{~cm}\right)$ e quatro modalidades de cultivo (MCS - cultivo do milho solteiro; MBL - cultivo do milho com B. brizantha na linha de semeadura; BEM - cultivo do milho com $B$. brizantha na entrelinha; e MBLE - cultivo do milho com $B$. brizantha simultaneamente na linha e na entrelinha). Foram avaliados a produtividade de matéria seca da forrageira, a caracterização fitossociológica, a incidência e o controle de plantas daninhas. O cultivo MBLE a $90 \mathrm{~cm}$ foi a modalidade de consorciação que proporcionou maior produção de palhada. A presença de $B$. brizantha em cultivo consorciado diminuiu a densidade de plantas daninhas. A utilização do cultivo consorciado do milho com $B$. brizantha na linha+entrelinha proporcionou indice de controle de $95 \%$, independentemente do espaçamento utilizado.
\end{abstract}

Palavras-chave: distribuição espacial de plantas, consorciação milho-braquiária, produtividade de matéria seca, palhada.

\begin{abstract}
Intercropping corn with tropical forages under no-tillage can decrease weed incidence as a result of high phytomass production and allelopathy provided by the superficial deposition of straw in the soil. This work aimed to evaluate the influence of intercropping modalities of corn with Brachiaria brizantha in two sowing spacings under no-tillage system on the weed population. The experiment was carried out under field conditions in 2002-2003 and 2003-2004, at the College of Agricultural Science/UNESP in Botucatu-SP-Brazil. The experiment was arranged in a randomized complete block design in a $2 x 4$ factorial scheme with four replications. The treatments consisted of two spacings between the corn rows $(E 1-0.45 m$ and E2-0.90m) and four tillage modalities (MCS-single corn tillage, MBL-corn tillage with B. brizantha in the sowing row, MBE-corn tillage with B. brizantha in the spacing between two rows and $M B L E$-corn tillage with B. brizantha simultaneously in the row and interrow).
\end{abstract}

Recebido para publicação em 5.2.2007 e na forma revisada em 3.1.2008.

2 Engo-Agr - ${ }^{-}$, Dr., Programa de Pós-Graduação em Agricultura da Faculdade de Ciências Agronômicas (FCA) da Universidade Estadual Paulista (UNESP), campus de Botucatu, Caixa Postal 237, 18603-970 Botucatu-SP, <borghi@fca.unesp.br, neumarcio@fca.unesp.br>; ${ }^{3}$ Engo-Agroo., Professor do Dep. de Produção Vegetal da FCA/UNESP, bolsista CNPq, $<$ crusciol@fca.unesp.br> autor correspondente; ${ }^{4}$ Eng -Agr ${ }^{0}$., Dr., Pesquisador da Agência Paulista de Tecnologia do Agronegócio (APTA), Pólo Regional do Extremo Oeste, Caixa Postal 67 - 16900-970, Andradina-SP, <gpmateus@apta.sp.gov.br>.

Planta Daninha, Viçosa-MG, v. 26, n. 3, p. 559-568, 2008 
Forage dry matter production, phyto-sociological characterization, and weed incidence and control were evaluated. Corn tillage with B.brizantha simultaneously in the row and interrow at $0.90 m$ spacing provided highest straw production. In addition, the presence of B.brizantha in the intercropping decreased weed density. Corn intercropping with B. brizantha provided $95 \%$ weed control regardless of type of sowing.

Keywords: spatial distribution, corn-grass intercropping, dry matter productivity, straw.

\section{INTRODUÇÃO}

Aliado ao plantio direto, o sistema de integração agricultura-pecuária tem contribuído para a viabilidade do setor agropecuário, uma vez que possibilita o fornecimento de alimento na época seca do ano (Mello et al., 2004).

$\mathrm{Na}$ região do cerrado brasileiro, as áreas utilizadas para produção de grãos permanecem em pousio aproximadamente oito meses, quando se adota apenas uma safra por ano agrícola, em virtude das condições climáticas, devido principalmente à deficiência hídrica (Aidar et al., 2003). Em regiões onde é possivel o cultivo de safrinha, pode-se optar pela produção de culturas forrageiras na entressafra em sucessão à cultura anual de verão, sendo semeada em fevereiro-março, como, por exemplo, as culturas do milho safrinha ou do sorgo, porém, em virtude do inverno com ausência de precipitação pluvial, este cultivo torna-se inadequado.

Entre as modalidades de integração agricultura-pecuária utilizadas no Brasil, destacase o cultivo consorciado de espécies forrageiras tropicais, como Brachiaria brizantha, com culturas como milho, soja, arroz, feijão e sorgo (Portes et al., 2000; Jakelaitis et al., 2004). Neste sistema de cultivo, a espécie forrageira é manejada como planta anual, sendo utilizada para produção de forragem após a colheita da cultura produtora de grãos e, em seguida, para formação de palha para semeadura da próxima safra de verão no sistema plantio direto.

A semeadura direta é caracterizada pelo reduzido revolvimento do solo e a formação de uma cobertura de restos vegetais sobre a superficie do solo. A manutenção dos restos vegetais na superfície do solo, além de protegê-lo da radiação solar, dissipa a energia de impacto das gotas de chuva, reduz a evaporação da água e aumenta a eficiência da ciclagem dos nutrientes, podendo ainda modificar e reduzir significativamente a intensidade de infestação de plantas daninhas em áreas agrícolas, devido às alterações das condições de germinação das sementes e emergência das plântulas, em razão do efeito físico da cobertura e da liberação de substâncias alelopáticas (Araújo \& Rodrigues, 2000; Severino \& Christoffoleti, 2001; Jakelaitis et al., 2003; Mateus et al., 2004; Trezzi \& Vidal, 2004). A capacidade de supressão de plantas daninhas por culturas de cobertura é bastante conhecida e explorada, embora seja pouco pesquisada a importância relativa dos efeitos de natureza física, química e biológica sobre esse fenômeno (Trezzi \& Vidal, 2004).

O cultivo consorciado do milho com forrageiras pode promover a supressão da emergência das plantas daninhas em virtude da rapidez de produção de massa dessas espécies no período de estabelecimento, ou seja, após a colheita da cultura produtora de grãos. O manejo de plantas daninhas na cultura do milho pode ser melhorado com a adoção de espécies de plantas forrageiras que convivam e se desenvolvam nas entrelinhas da cultura. Além de auxiliar na supressão da comunidade infestante, esse consórcio pode antecipar a formação da pastagem que será destinada ao consumo animal, fato que contribui para maximizar o uso da terra, com conseqüente possibilidade de aumento da receita a ser obtida (Severino et al., 2006a).

Diversas pesquisas evidenciam a utilização do cultivo consorciado do milho com forrageiras tropicais, em especial espécies do gênero Brachiaria (Freitas et al., 2005b; Jakelaitis et al., 2005a; Severino et al., 2006a). De acordo com Jakelaitis et al. (2005b), para o sucesso da aplicação deste sistema de produção, devem- 
se levar em consideração as especificidades do local de cultivo, como o solo e o clima.

Este trabalho objetivou avaliar a influência da distribuição espacial de Brachiaria brizantha na cultura do milho cultivado no sistema plantio direto na palha sobre a população de plantas daninhas.

\section{MATERIAL E MÉTODOS}

O experimento foi realizado nos anos agrícolas 2002/03 e 2003/04, na Fazenda Experimental Lageado, pertencente à Faculdade de Ciências Agronômicas, UNESP, campus de Botucatu-SP, apresentando as seguintes coordenadas: $22^{\circ} 51^{\prime} \mathrm{S}$ de latitude, $48^{\circ} 26^{\prime} \mathrm{W}$ de longitude e $786 \mathrm{~m}$ de altitude. O clima predominante na região é do tipo $\mathrm{Cfa}$, segundo a classificação climática de Köppen, ou seja, clima temperado (mesotérmico), região constantemente úmida, com inverno seco e verão quente e chuvoso (Martins, 2003).

O solo da área experimental é classificado como Nitossolo Vermelho Estruturado (Embrapa, 1999), cultivado há seis anos no sistema plantio direto na palha.

O delineamento experimental foi de blocos casualizados, em esquema fatorial $2 \times 4$, com quatro repetições. Os tratamentos foram constituídos pela combinação de dois espaçamentos entre linhas de milho (E1 - $45 \mathrm{~cm}$ e E2 $-90 \mathrm{~cm}$ ) e quatro modalidades de cultivo (MBL - cultivo do milho $\operatorname{com} B$. brizantha na linha de semeadura; MBE - cultivo do milho $\operatorname{com} B$. brizantha na entrelinha; MBLE - cultivo do milho com $B$. brizantha simultaneamente na linha e na entrelinha; e MCS - cultivo do milho solteiro testemunha).

Cada unidade experimental continha área total de $120 \mathrm{~m}^{2}$ (20 m de comprimento x $6 \mathrm{~m}$ de largura). O híbrido de milho utilizado no presente trabalho foi o AG 9010, e a espécie forrageira utilizada em consórcio foi a Brachiaria brizantha cv. Marandu.

As semeaduras das culturas foram realizadas em 13/12/2002 e 13/12/2003, por meio de semeadora adubadora para plantio direto, com cinco linhas espaçadas de $45 \mathrm{~cm}$ e três linhas espaçadas de $90 \mathrm{~cm}$, objetivando estande de 55.000 plantas ha-1, adotando-se $5 \mathrm{~cm}$ co- mo profundidade de semeadura. A densidade de semeadura de Brachiaria brizantha foi de $10 \mathrm{~kg} \mathrm{ha}^{-1}(\mathrm{VC}=34 \%)$, independentemente da forma de consorciação, sendo as sementes misturadas ao adubo, acondicionadas no compartimento do adubo da semeadora e distribuídas na profundidade de $8 \mathrm{~cm}$, localizandose dessa forma abaixo da semente de milho, seguindo as recomendações de Kluthcouski et al. (2000).

A emergência do milho ocorreu em 19/ $12 / 2002$ e $22 / 12 / 2003$, enquanto $B$. brizantha teve sua emergência em 5/1/2003 e 28/12/ 2003.

No espaçamento de $90 \mathrm{~cm}$, a semeadura de $B$. brizantha na entrelinha e linha+entrelinha foi realizada utilizando todos os carrinhos da semeadora a $45 \mathrm{~cm}$. Assim, alternadamente, um carrinho distribuia somente milho e outro somente braquiária (MBLE - cultivo do milho com Brachiaria brizantha na entrelinha) ou milho e braquiária e outro somente braquiária (MBLE - cultivo do milho com Brachiaria brizantha simultaneamente na linha e na entrelinha). Quanto ao espaçamento de $45 \mathrm{~cm}$, a semeadura de $B$. brizantha na entrelinha e linha + entrelinha foi realizada utilizando todos os carrinhos da semeadora a $45 \mathrm{~cm}$. No entanto, houve necessidade de passar a semeadora na entrelinha da primeira passada, estabelecendo-se assim o espaçamento de $22,5 \mathrm{~cm}$ entre a linha de milho e a de braquiária para os tratamentos MBE e MBLE.

A colheita do milho no ano agrícola 2002/ 03 e 2003/04 foi feita aos 125 e 122 dias após a emergência do milho, respectivamente.

Vale ressaltar que no segundo ano (2003/ 2004) o experimento foi instalado na mesma área, ou seja, todos os tratamentos foram implantados nas mesmas unidades experimentais provenientes do ano anterior. Antes da dessecação das forrageiras, no mês de novembro de 2003, foi efetuada a avaliação para quantificação da produção de matéria seca de $B$. brizantha. Para isso, efetuou-se a coleta da parte aérea das forrageiras, utilizando moldura metálica de $1 \mathrm{~m}^{2}$ de área, em duas amostragens por unidade experimental. O material coletado foi seco em estufa de circulação forçada de ar a $60{ }^{\circ} \mathrm{C}$; em seguida, foi pesado, e os dados, transformados em $\mathrm{kg} \mathrm{ha}^{-1}$. No ano agrícola 
2003/04, a avaliação da produção de matéria seca de $B$. brizantha foi realizada no mês de novembro de 2004, adotando-se a mesma metodologia.

Simultaneamente à avaliação da produção de matéria seca de $B$. brizantha, realizou-se também a caracterização fitossociológica e a avaliação da comunidade infestante. Para isso, aplicou-se o método do quadrado inventário, utilizando-se quadros de $0,25 \mathrm{~m}^{2}(0,5 \times 0,5 \mathrm{~m})$, lançados ao acaso em cada parcela. No primeiro ano foram amostrados quatro quadros por parcela e, no segundo, apenas três quadros por parcela. Em cada quadro amostrado, as plantas daninhas foram identificadas segundo família, gênero e espécie; determinou-se também o número presente de cada espécie.

O levantamento das plantas daninhas foi realizado 45 dias após a colheita da cultura, em cada ano. A partir da contagem das espécies presentes, foram calculados os seguintes parâmetros fitossociológicos: densidade relativa $(\mathrm{Dr})$, freqüência relativa $(\mathrm{Fr})$, abundância relativa (Ar), índice de importância relativa (Ir), calculados segundo as fórmulas propostas por Mueller-Dombois \& Ellemberg (1974) e BraunBlanquet (1979).

De posse das médias, determinou-se a densidade e o controle de plantas daninhas em função dos tratamentos. A fórmula utilizada no cálculo de controle foi: $\mathrm{C}=[1-(\mathrm{I} / 100)]$, em que $\mathrm{C}$ é o controle de plantas daninhas, em \%; e I, a incidência de plantas daninhas ( $n^{\circ}$ de plantas daninhas observadas por espécie / $\mathrm{n}^{\circ}$ de plantas daninhas total), em \%.

Os resultados referentes à produção de matéria seca de Brachiaria brizantha, densidade de plantas daninhas e porcentagem de controle foram submetidos à análise de variância, e as médias, comparadas pelo teste DMS a 5\% de probabilidade.

\section{RESULTADOS E DISCUSSÃO}

Na Tabela 1 encontram-se os valores médios de produção de matéria seca de $B$. brizantha ao final de cada ano agrícola. Constata-se que houve efeito dos sistemas de consorciação em relação aos espaçamentos somente no espaçamento de $90 \mathrm{~cm}$. No espaçamento de $45 \mathrm{~cm}$, as modalidades de cultivo não diferiram estatisticamente.
Tabela 1 - Quantidade de palhada presente na área, em função do sistema de cultivo do milho, em diferentes espaçamentos. Botucatu-SP, 2002/03 e 2003/04

\begin{tabular}{|c|c|c|}
\hline \multirow{2}{*}{ Tratamento } & \multicolumn{2}{|c|}{ Produção de Matéria Seca $\left(\mathrm{kg} \mathrm{ha}^{-1}\right)$} \\
\cline { 2 - 3 } & $\begin{array}{c}\text { Ano agrícola } \\
2002 / 03\end{array}$ & $\begin{array}{c}\text { Ano Agrícola } \\
2003 / 04\end{array}$ \\
\hline Espaçamentos (E) & & \\
\hline 90 & $8.143 \mathrm{~b}$ & $9.333 \mathrm{a}$ \\
\hline 45 & $9.814 \mathrm{a}$ & $8.778 \mathrm{a}$ \\
\hline Modalidades de Cultivo (MC) & & \\
\hline MS & $3.000 \mathrm{~b}$ & $2.030 \mathrm{c}$ \\
\hline MBL & $8.505 \mathrm{a}$ & $8.000 \mathrm{~b}$ \\
\hline BEM & $8.321 \mathrm{a}$ & $10.500 \mathrm{a}$ \\
\hline MBLE & $10.110 \mathrm{a}$ & $8.666 \mathrm{ab}$ \\
\hline & \multicolumn{2}{|c|}{ Valor de DMS } \\
\hline E & 1.556 & 1.503 \\
\hline MC & 1.905 & 1.841 \\
\hline CV (\%) & 19,91 & 19,08 \\
\hline
\end{tabular}

Médias seguidas por letras iguais nas colunas (minúsculas) não diferem entre si pelo teste DMS a 5\%. MS - milho solteiro; MBL - milho $+B$. brizantha na linha; MBE - milho + B. brizantha na entrelinha; MBLE - Milho $+B$. brizantha na linha e entrelinha.

Ao analisar o desdobramento da interação entre modalidades de consorciação e espaçamentos (Tabela 2), pode-se verificar que, nos dois anos de condução do experimento, a maior produtividade de matéria seca de $B$. brizantha ocorreu no consórcio milho $+B$. brizantha na linha + entrelinha (MBLE), o que está relacionado ao fato de que o maior espaçamento proporcionou maior incidência da radiação solar

Tabela 2 - Desdobramento da interação modalidades de cultivo $\mathrm{x}$ espaçamentos na cultura do milho consorciado com Brachiaria brizantha para quantidade de palhada $\left(\mathrm{kg} \mathrm{ha}^{-1}\right)$ presente na superfície do solo no sistema plantio direto. Botucatu-SP, 2002/03 e 2003/04

\begin{tabular}{|c|c|c|c|c|}
\hline \multirow{2}{*}{$\begin{array}{c}\text { Espaçamento } \\
(\mathrm{cm})\end{array}$} & \multicolumn{4}{|c|}{ Ano agrícola 2002/03 } \\
\cline { 2 - 5 } & $\mathrm{MS}$ & MBL & MBE & MBLE \\
\hline 90 & $2700 \mathrm{aC}$ & $9034 \mathrm{aAB}$ & $8749 \mathrm{aB}$ & $11659 \mathrm{aA}$ \\
\hline 45 & $3300 \mathrm{aB}$ & $7977 \mathrm{aA}$ & $7893 \mathrm{aA}$ & $8560 \mathrm{bA}$ \\
\hline DMS & \multicolumn{5}{|c|}{ Ano agrícola $2003 / 04$} \\
\hline & \multicolumn{5}{|c|}{$7000 \mathrm{aB}$} & $8166 \mathrm{aB}$ & $12833 \mathrm{aA}$ \\
\hline 90 & $2000 \mathrm{aC}$ & $7005 \mathrm{aA}$ & $9166 \mathrm{aA}$ \\
\hline 45 & $2060 \mathrm{aC}$ & $9000 \mathrm{aA}$ & $8167 \mathrm{bA}$ & 9.604 \\
\hline DMS & \multicolumn{5}{|c|}{} \\
\hline
\end{tabular}

Médias seguidas por mesma letra na linha (maiúscula) e na coluna (minúscula) não diferem entre si pelo teste DMS a 5\%. MS milho solteiro; MBL - milho + B. brizantha na linha; MBE milho $+B$. brizantha na entrelinha; MBLE - milho + B. brizantha na linha e entrelinha. 
e menor competição com a cultura do milho, desencadeando maior acúmulo de biomassa por parte da forrageira. De acordo com Severino et al. (2006a), a alta produtividade das forrageiras - mesmo quando em competição com plantas daninhas e, principalmente, com o milho - se deve à semeadura simultânea das culturas, permitindo maior acúmulo de biomassa pela forrageira devido a um menor efeito de competição interespecífica, diminuindo assim os recursos necessários para o desenvolvimento das plantas daninhas.

No ano 2003/04, o tratamento MBLE proporcionou maior produtividade de matéria seca, havendo incremento de $5.833 \mathrm{~kg} \mathrm{ha}^{-1} \mathrm{em}$ relação ao tratamento consorciado com menor produtividade (Tabela 2). Assim como constatado por Severino et al. (2006b), a produtividade de matéria seca de $B$. brizantha proporcionada pelo cultivo consorciado com milho indica que os efeitos de competição entre estas espécies e as plantas daninhas foram pouco significativos, quando comparados com o cultivo do milho solteiro, sendo então destacada a viabilidade do cultivo consorciado envolvendo essas duas espécies.

Na Tabela 3 estão descritas as espécies de plantas daninhas identificadas na área de produção do milho consorciado $\operatorname{com} B$. brizantha, nos anos agrícolas 2002/03 e 2003/04, com sua respectiva família, nome científico, nome vulgar e código internacional, de acordo com Kissmann \& Groth $(1997,1999,2000)$. Foram identificadas 17 espécies, distribuídas em nove famílias, destacando-se as famílias Compositae, com cinco espécies, Poaceae, com quatro espécies, e Lamiaceae, com duas espécies. As famílias Amaranthaceae, Commelinaceae, Cruciferae, Malvaceae, Oxalidaceae e Rubiaceae apresentaram apenas uma espécie.

Pelos resultados de densidade de plantas e porcentagem de controle (Tabela 4), pode-se constatar que elas sofreram influência das modalidades de consorciação empregadas.

Entretanto, independentemente do sistema de consórcio, a densidade de plantas é menor e conseqüentemente o controle é maior, em relação ao cultivo do milho solteiro. Contudo, a maior densidade de plantas daninhas verificada no espaçamento de $45 \mathrm{~cm}$ pode ser atribuída à maior emergência destas na linha de semeadura, onde ocorre revolvimento do solo, bem como o menor desenvolvimento de $B$. brizantha na entrelinha se deve à semeadura mais profunda no consórcio simultâneo e ao maior efeito do sombreamento da cultura do milho sobre a forrageira, o que pode reduzir

Tabela 3 - Identificação das plantas daninhas avaliadas nos anos agrícolas 2002/03 e 2003/04. Botucatu-SP

\begin{tabular}{|c|c|c|c|}
\hline Família & Espécie & Nome vulgar & Código \\
\hline Amaranthaceae & Alternanthera tenella Colla & Apaga-fogo & ALRTE \\
\hline Commelinaceae & Commelina bengalensis L. & Trapoeraba & COMBE \\
\hline Compositae & $\begin{array}{l}\text { Acanthospermum australe (Loef.) Kuntze } \\
\text { Bidens pilosa L. } \\
\text { Emilia sonchifolia (L.) DC. } \\
\text { Sonchus oleraceus L. } \\
\text { Galinsoga parviflora Cav. }\end{array}$ & $\begin{array}{l}\text { Carrapicho-rasteiro } \\
\text { Picão-preto } \\
\text { Falsa-serralha } \\
\text { Serralha } \\
\text { Picão-branco } \\
\end{array}$ & $\begin{array}{l}\text { ACNAU } \\
\text { BIDPI } \\
\text { EMISO } \\
\text { SONOL } \\
\text { GASPA }\end{array}$ \\
\hline Cruciferae & Raphanus sativus L. & Nabiça & RAPSV \\
\hline Laminaceae & $\begin{array}{l}\text { Leonotis nepetaefolia (L.) W. T. Aiton } \\
\text { Leonurus sibiricus L. }\end{array}$ & $\begin{array}{l}\text { Cordão-de-frade } \\
\text { Rubim }\end{array}$ & $\begin{array}{l}\text { LEONE } \\
\text { LECSI }\end{array}$ \\
\hline Malvaceae & Sida rhombifolia $\mathrm{L}$. & Guanxuma & SIDRH \\
\hline Oxalidaceae & Oxalis latifolia unth & Trevo-azedo & OXALA \\
\hline Poaceae & $\begin{array}{l}\text { Brachiaria plantaginea (Link) Hitchc. } \\
\text { Digitaria insularis (L.) Fedde } \\
\text { Panicum sp. } \\
\text { Rhynchelytrum repens (Willd.) Hubb. }\end{array}$ & $\begin{array}{c}\text { Capim-marmelada } \\
\text { Capim-amargoso } \\
\text {----- } \\
\text { Capim-favorito } \\
\end{array}$ & $\begin{array}{c}\text { BRAPL } \\
\text { DIGIN } \\
--- \\
\text { RHYRE }\end{array}$ \\
\hline Rubiaceae & Richardia brasiliensis Gómez & Poaia-branca & RICHBR \\
\hline
\end{tabular}


Tabela 4 - Densidade e controle de plantas daninhas, em função do sistema de cultivo do milho em diferentes espaçamentos. Botucatu-SP, 2002/03 e 2003/04

\begin{tabular}{|l|c|c|c|c|}
\hline \multirow{2}{*}{$\begin{array}{c}\text { Espaçamento } \\
(\mathrm{E})\end{array}$} & \multicolumn{2}{|c|}{$\begin{array}{c}\text { Densidade } \\
\left(\mathrm{n}^{\mathrm{0}} \text { }\right.\end{array}$} & \multicolumn{2}{c|}{$\begin{array}{c}\text { Controle } \\
(\%)\end{array}$} \\
\cline { 2 - 5 } & $2002 / 03$ & $2003 / 04$ & $2002 / 03$ & $2003 / 04$ \\
\hline 90 & $2,45 \mathrm{~b}$ & $2,07 \mathrm{a}$ & $66 \mathrm{a}$ & $75 \mathrm{a}$ \\
\hline 45 & $4,13 \mathrm{a}$ & $2,57 \mathrm{a}$ & $60 \mathrm{a}$ & $73 \mathrm{a}$ \\
\hline & \multicolumn{4}{|c|}{ Modalidades de Cultivo (MC) } \\
\hline MS & $6,23 \mathrm{a}$ & $8,15 \mathrm{a}$ & $0 \mathrm{c}$ & $0 \mathrm{~b}$ \\
\hline MBL & $2,55 \mathrm{~b}$ & $0,34 \mathrm{~b}$ & $85 \mathrm{ab}$ & $99 \mathrm{a}$ \\
\hline MBE & $2,48 \mathrm{~b}$ & $0,53 \mathrm{~b}$ & $73 \mathrm{~b}$ & $98 \mathrm{a}$ \\
\hline MBLE & $2,55 \mathrm{~b}$ & $0,25 \mathrm{~b}$ & $95 \mathrm{a}$ & $98 \mathrm{a}$ \\
\hline & \multicolumn{5}{|c|}{ Valor de DMS } \\
\hline E & 1,28 & 1,11 & 9,80 & 2,34 \\
\hline MC & 1,81 & 1,57 & 13,87 & 3,32 \\
\hline CV (\%) & 53,01 & 65,04 & 21,09 & 4,32 \\
\hline
\end{tabular}

Médias seguidas por letras iguais nas colunas (minúsculas) não diferem entre si pelo teste DMS a 5\%. MS - milho solteiro; MBL - milho $+B$. brizantha na linha; MBE - milho $+B$. brizantha na entrelinha; MBLE - milho $+B$. brizantha na linha e entrelinha. 1/ Dados transformados em $\sqrt{ } 0,5$.

a competição desta em relação às plantas daninhas, quando comparado ao espaçamento de $90 \mathrm{~cm}$ (Jakelaitis et al., 2005b).

Analisando o desdobramento da interação modalidades de consorciação em relação ao espaçamento entrelinhas adotado (Tabela 5), observa-se que no ano agrícola 2002/03 as modalidades de consorciação promoveram maior controle de plantas daninhas, comparada ao plantio do milho solteiro.

De acordo com a análise fitossociológica da comunidade de plantas daninhas identificadas no ano agrícola 2002/03 (Tabela 6), podese verificar que houve predominio das

Tabela 5 - Desdobramento da interação modalidades de cultivo $\mathrm{x}$ espaçamentos na cultura do milho consorciado com Brachiaria brizantha, para controle de plantas daninhas (\%). Botucatu-SP, 2002/03 e 2003/04

\begin{tabular}{|l|c|c|c|c|}
\hline \multirow{2}{*}{$\begin{array}{c}\text { Espaçamento } \\
(\mathrm{cm})\end{array}$} & $\mathrm{MS}$ & $\mathrm{MBL}$ & $\mathrm{MBE}$ & MBLE \\
\cline { 2 - 5 } Controle (\%) \\
\hline 90 & $0 \mathrm{aB}$ & $88 \mathrm{aA}$ & $81 \mathrm{aA}$ & $95 \mathrm{aA}$ \\
\hline 45 & $0 \mathrm{aC}$ & $81 \mathrm{aAB}$ & $64 \mathrm{aB}$ & $95 \mathrm{aA}$ \\
\hline DMS & \multicolumn{5}{|c|}{20} \\
\hline
\end{tabular}

Médias seguidas por mesma letra na linha (maiúscula) e na coluna (minúscula) não diferem entre si pelo teste DMS a $5 \%$. MS milho solteiro; MBL - milho $+B$. brizantha na linha; MBE milho $+B$. brizantha na entrelinha; MBLE - milho + B. brizantha na linha e entrelinha. espécies dicotiledôneas em relação às monocotiledôneas, em todos os tratamentos. Constatação semelhante foi descrita por Mateus et al. (2004), os quais observaram que, mesmo com o aumento na quantidade de palha sobre a superficie do solo, houve predominio de folhas largas em relação às gramíneas, o que pode ser atribuído ao banco de sementes existentes na área experimental ou ao manejo dos herbicidas de anos anteriores, além de efeitos alelopáticos.

Pelos resultados da Tabela 6, pode-se constatar que no ano agrícola 2002/03, no milho semeado no espaçamento de $45 \mathrm{~cm}$, a espécie Leonuruns sibiricus apresentou o maior valor de importância relativa (IR) nos sistemas MS, MBL e MBLE, com valores na ordem de 118,2, 141,3 e $170,3 \%$, respectivamente. No sistema MBE, Sida rhombifolia foi a espécie que apresentou o maior valor de importância relativa $(84,1 \%)$. No milho semeado no espaçamento de $90 \mathrm{~cm}$, Alternanthera tenella foi a espécie que obteve o maior valor de IR nos sistemas de consórcios MBL, MBE e MBLE, com valores em torno de 125,0, 91,8 e 91,7\%, respectivamente. Sonchus oleraceus também apresentou valor de IR acima de $90 \%$ no sistema de consórcio MBLE. Para o MS, Leonurus sibiricus foi a espécie que apresentou o maior valor de IR $(74,2 \%)$.

Na análise fitossociológica da comunidade de plantas daninhas identificadas no ano agrícola de 2003/04 (Tabela 7), pode-se verificar que houve também predomínio das espécies dicotiledôneas em relação às monocotiledôneas em todos os tratamentos. No milho semeado no espaçamento de $45 \mathrm{~cm}, L$. sibiricus foi a espécie que apresentou o maior valor de IR no sistema MS: em torno de $151,4 \%$. Nos tratamentos consorciados MBL e MBLE, foi identificada apenas a espécie $L$. sibiricus, enquanto no sistema de consórcio MBE foram identificadas duas espécies: L. sibiricus e Raphanus sativus. No milho semeado no espaçamento de $90 \mathrm{~cm}$, a espécie que apresentou o maior valor de IR no sistema MS foi $L$. sibiricus: em torno de $133,7 \%$. No sistema de consórcio MBL foram identificadas somente as espécies $L$. sibiricus e Bidens pilosa; no consórcio BEM, foi identificada apenas a espécie Leonotis nepetaefolia. Não foi encontrada nenhuma planta daninha no sistema de consórcio MBLE. 
Tabela 6 - Análise fitossociológica da comunidade de plantas daninhas identificadas no ano agrícola 2002/03

\begin{tabular}{|c|c|c|c|c|c|c|c|}
\hline \multirow{2}{*}{ Tratamento } & \multirow{2}{*}{ Espécie } & \multirow{2}{*}{$\begin{array}{l}\text { Quadros } \\
\text { ocupados }\end{array}$} & \multirow{2}{*}{$\begin{array}{c}\mathrm{N}^{\mathrm{o}} \mathrm{de} \\
\text { indivíduos }\end{array}$} & $\mathrm{Fr}$ & $\mathrm{Dr}$ & $\mathrm{Ar}$ & $\mathrm{Ir}$ \\
\hline & & & & $(\%)$ & $(\%)$ & $(\%)$ & $(\%)$ \\
\hline \multicolumn{8}{|c|}{ Espaçamento $-45 \mathrm{~cm}$} \\
\hline \multirow{6}{*}{ Milho solteiro } & Leonurus sibiricus & 7 & 108 & 20,6 & 49,5 & 48,1 & 118,2 \\
\hline & Raphanus sativus & 11 & 49 & 32,4 & 22,5 & 13,9 & 68,7 \\
\hline & Commelina benghalensis & 6 & 35 & 17,6 & 16,1 & 18,2 & 51,9 \\
\hline & Alternanthera tenella & 5 & 18 & 14,7 & 8,3 & 11,2 & 34,2 \\
\hline & Sida rhombifolia & 4 & 7 & 11,8 & 3,2 & 5,5 & 20,4 \\
\hline & Digitaria insularis & 1 & 1 & 2,9 & 0,5 & 3,1 & 6,5 \\
\hline Total & & - & 218 & 100,0 & 100,0 & 100,0 & 300,0 \\
\hline \multirow{5}{*}{ Milho + Brachiaria na linha } & Leonurus sibiricus & 9 & 35 & 45,0 & 61,4 & 34,9 & 141,3 \\
\hline & Commelina benghalensis & 4 & 9 & 20,0 & 15,8 & 20,2 & 56,0 \\
\hline & Raphanus sativus & 4 & 8 & 20,0 & 14,0 & 18,0 & 52,0 \\
\hline & Sida rhombifolia & 2 & 4 & 10,0 & 7,0 & 18,0 & 35,0 \\
\hline & Acanthospermum australe & 1 & 1 & 5,0 & 1,8 & 9,0 & 15,7 \\
\hline Total & & - & 57 & 100,0 & 100,0 & 100,0 & 300,0 \\
\hline \multirow{6}{*}{$\begin{array}{c}\text { Milho + Brachiaria na } \\
\text { entrelinha }\end{array}$} & Sida rhombifolia & 6 & 14 & 33,3 & 35,0 & 15,7 & 84,1 \\
\hline & Leonurus sibiricus & 2 & 9 & 11,1 & 22,5 & 30,3 & 63,9 \\
\hline & Alternanthera tenella & 4 & 7 & 22,2 & 17,5 & 11,8 & 51,5 \\
\hline & Raphanus sativus & 4 & 5 & 22,2 & 12,5 & 8,4 & 43,1 \\
\hline & Oxalis latifolia & 1 & 4 & 5,6 & 10,0 & 27,0 & 42,5 \\
\hline & Commelina benghalensis & 1 & 1 & 5,6 & 2,5 & 6,7 & 14,8 \\
\hline Total & & - & 40 & 100,0 & 100,0 & 100,0 & 300,0 \\
\hline \multirow{5}{*}{$\begin{array}{c}\text { Milho }+ \text { Brachiaria na linha } \\
\text { e entrelinha }\end{array}$} & Leonurus sibiricus & 5 & 35 & 41,7 & 76,1 & 52,5 & 170,3 \\
\hline & Alternanthera tenella & 3 & 4 & 25,0 & 8,7 & 10,0 & 43,7 \\
\hline & Raphanus sativus & 2 & 4 & 16,7 & 8,7 & 15,0 & 40,4 \\
\hline & Commelina benghalens is & 1 & 2 & 8,3 & 4,3 & 15,0 & 27,7 \\
\hline & Sida rhombifolia & 1 & 1 & 8,3 & 2,2 & 7,5 & 18,0 \\
\hline Total & & - & 46 & 100,0 & 100,0 & 100,0 & 300,0 \\
\hline \multicolumn{8}{|c|}{ Espaçamento $-90 \mathrm{~cm}$} \\
\hline \multirow{9}{*}{ Milho solteiro } & Leonurus sibiricus & 7 & 38 & 17,1 & 32,5 & 24,7 & 74,2 \\
\hline & Raphanus sativus & 7 & 23 & 17,1 & 19,7 & 14,9 & 51,7 \\
\hline & Alternanthera tenella & 7 & 16 & 17,1 & 13,7 & 10,4 & 41,1 \\
\hline & Sida rhombifolia & 7 & 15 & 17,1 & 12,8 & 9,7 & 39,6 \\
\hline & Commelina benghalensis & 5 & 11 & 12,2 & 9,4 & 10,0 & 31,6 \\
\hline & Rhynchelytrum repens & 2 & 6 & 4,9 & 5,1 & 13,6 & 23,6 \\
\hline & Acanthospermum australe & 3 & 5 & 7,3 & 4,3 & 7,6 & 19,2 \\
\hline & Digitaria insularis & 2 & 2 & 4,9 & 1,7 & 4,5 & 11,1 \\
\hline & Emilia sonchifolia & 1 & 1 & 2,4 & 0,9 & 4,5 & 7,8 \\
\hline Total & & - & 117 & 100,0 & 100,0 & 100,0 & 300,0 \\
\hline \multirow{4}{*}{ Milho + Brachiaria na linha } & Alternanthera tenella & 3 & 6 & 50,0 & 50,0 & 25,0 & 125,0 \\
\hline & Leonurus sibiricus & 1 & 3 & 16,7 & 25,0 & 37,5 & 79,2 \\
\hline & Panicum $s p$ & 1 & 2 & 16,7 & 16,7 & 25,0 & 58,3 \\
\hline & Sida rhombifolia & 1 & 1 & 16,7 & 8,3 & 12,5 & 37,5 \\
\hline Total & & - & 12 & 100,0 & 100,0 & 100,0 & 300,0 \\
\hline \multirow{5}{*}{$\begin{array}{c}\text { Milho + Brachiaria na } \\
\text { entrelinha }\end{array}$} & Alternanthera tenella & 2 & 7 & 25,0 & 35,0 & 31,8 & 91,8 \\
\hline & Leonurus sibiricus & 2 & 6 & 25,0 & 30,0 & 27,3 & 82,3 \\
\hline & Commelina benghalensis & 2 & 5 & 25,0 & 25,0 & 22,7 & 72,7 \\
\hline & Emilia sonchifolia & 1 & 1 & 12,5 & 5,0 & 9,1 & 26,6 \\
\hline & Raphanus sativus & 1 & 1 & 12,5 & 5,0 & 9,1 & 26,6 \\
\hline Total & & - & 20 & 100,0 & 100,0 & 100,0 & 300,0 \\
\hline \multirow{4}{*}{$\begin{array}{c}\text { Milho }+ \text { Brachiaria na linha } \\
\text { e entrelinha }\end{array}$} & Alternanthera tenella & 1 & 2 & 25,0 & 33,3 & 33,3 & 91,7 \\
\hline & Sonchus oleraceus & 1 & 2 & 25,0 & 33,3 & 33,3 & 91,7 \\
\hline & Bidens pilosa & 1 & 1 & 25,0 & 16,7 & 16,7 & 58,3 \\
\hline & Raphanus sativus & 1 & 1 & 25,0 & 16,7 & 16,7 & 58,3 \\
\hline Total & & - & 6 & 100,0 & 100,0 & 100,0 & 300,0 \\
\hline
\end{tabular}


Tabela 7 - Análise fitossociológica da comunidade de plantas daninhas identificadas no ano agrícola 2003/04. Botucatu-SP

\begin{tabular}{|c|c|c|c|c|c|c|c|}
\hline \multirow{2}{*}{ Tratamento } & \multirow{2}{*}{ Espécie } & \multirow{2}{*}{$\begin{array}{l}\text { Quadro } \\
\text { ocupado }\end{array}$} & \multirow{2}{*}{$\begin{array}{c}\mathrm{N}^{\mathrm{o}} \mathrm{de} \\
\text { indivíduos }\end{array}$} & Fr & Dr & $\mathrm{Ar}$ & $\mathrm{Ir}$ \\
\hline & & & & $(\%)$ & $(\%)$ & $(\%)$ & $(\%)$ \\
\hline \multicolumn{8}{|c|}{ Espaçamento $-45 \mathrm{~cm}$} \\
\hline \multirow{10}{*}{ Milho solteiro } & Leonurus sibiricus & 9 & 188 & 29,0 & 76,7 & 45,6 & 151,4 \\
\hline & Sida rhombifolia & 5 & 13 & 16,1 & 5,3 & 5,7 & 27,1 \\
\hline & Rhynchelytrum repens & 2 & 13 & 6,5 & 5,3 & 14,2 & 25,9 \\
\hline & Alternanthera tenella & 3 & 10 & 9,7 & 4,1 & 7,3 & 21,0 \\
\hline & Emilia sonchifolia & 1 & 5 & 3,2 & 2,0 & 10,9 & 16,2 \\
\hline & Digitaria insularis & 2 & 5 & 6,5 & 2,0 & 5,5 & 13,9 \\
\hline & Brachiaria plantaginea & 3 & 3 & 9,7 & 1,2 & 2,2 & 13,1 \\
\hline & Commelina benghalensis & 2 & 4 & 6,5 & 1,6 & 4,4 & 12,4 \\
\hline & Sonchus oleraceus & 2 & 2 & 6,5 & 0,8 & 2,2 & 9,5 \\
\hline & Raphanus sativus & 2 & 2 & 6,5 & 0,8 & 2,2 & 9,5 \\
\hline Total & & - & 245 & 100,0 & 100,0 & 100,0 & 300,0 \\
\hline \multirow[t]{2}{*}{ Milho + Brachiaria na linha } & Leonurus sibiricus & 1 & 1 & 1000 & 1000 & 1000 & 3000 \\
\hline & & & & & & & \\
\hline Total & & - & 1,00 & 100,0 & 100,0 & 100,0 & 300,0 \\
\hline \multirow{2}{*}{$\begin{array}{l}\text { Milho + Brachiaria na } \\
\text { entrelinha }\end{array}$} & Leonurus sibiricus & 2 & 4 & 66,7 & 80,0 & 66,7 & 213,3 \\
\hline & Raphanus sativus & 1 & 1 & 33,3 & 20,0 & 33,3 & 86,7 \\
\hline Total & & - & 5 & 100,0 & 100,0 & 100,0 & 300,0 \\
\hline \multirow{3}{*}{$\begin{array}{c}\text { Milho }+ \text { Brachiaria na linha e } \\
\text { entrelinha }\end{array}$} & & & & & & & \\
\hline & Leonurus sibiricus & 1 & 3 & 100,0 & 100,0 & 100,0 & 300,0 \\
\hline & & & & & & & \\
\hline Total & & - & 3 & 100,0 & 100,0 & 100,0 & 300,0 \\
\hline \multicolumn{8}{|c|}{ Espaçamento $-90 \mathrm{~cm}$} \\
\hline \multirow{12}{*}{ Milho solteiro } & Leonurus sibiricus & 10 & 129 & 25,6 & 69,4 & 38,7 & 133,7 \\
\hline & Sida rhombifolia & 4 & 15 & 10,3 & 8,1 & 11,3 & 29,6 \\
\hline & Digitaria insularis & 6 & 13 & 15,4 & 7,0 & 6,5 & 28,9 \\
\hline & Commelina benghalensis & 4 & 6 & 10,3 & 3,2 & 4,5 & 18,0 \\
\hline & Brachiaria plantaginea & 3 & 6 & 7,7 & 3,2 & 6,0 & 16,9 \\
\hline & Alternanthera tenella & 4 & 4 & 10,3 & 2,2 & 3,0 & 15,4 \\
\hline & Rhynchelytrum repens & 2 & 4 & 5,1 & 2,2 & 6,0 & 13,3 \\
\hline & Richardia brasiliensis & 1 & 3 & 2,6 & 1,6 & 9,0 & 13,2 \\
\hline & Galinsoga parviflora & 1 & 2 & 2,6 & 1,1 & 6,0 & 9,6 \\
\hline & Sonchus oleraceus & 2 & 2 & 5,1 & 1,1 & 3,0 & 9,2 \\
\hline & Bidens pilosa & 1 & 1 & 2,6 & 0,5 & 3,0 & 6,1 \\
\hline & Raphanus sativus & 1 & 1 & 2,6 & 0,5 & 3,0 & 6,1 \\
\hline Total & & - & 186 & 100,0 & 100,0 & 100,0 & 300,0 \\
\hline \multirow{2}{*}{ Milho + Brachiaria na linha } & Leonurus sibiricus & 1 & 1 & 50,0 & 50,0 & 50,0 & 150,0 \\
\hline & Bidens pilosa & 1 & 1 & 50,0 & 50,0 & 50,0 & 150,0 \\
\hline Total & & - & 2 & 100,0 & 100,0 & 100,0 & 300,0 \\
\hline \multirow{2}{*}{$\begin{array}{c}\text { Milho + Brachiaria na } \\
\text { entrelinha }\end{array}$} & & & & & & & \\
\hline & Leonotis nepetaefolia & 1 & 1 & 100,0 & 100,0 & 100,0 & 300,0 \\
\hline Total & & - & 1 & 100,0 & 100,0 & 100,0 & 300,0 \\
\hline \multirow{3}{*}{$\begin{array}{c}\text { Milho }+ \text { Brachiaria na linha e } \\
\text { entrelinha }\end{array}$} & & & & & & & \\
\hline & - & - & - & - & - & - & - \\
\hline & & & & & & & \\
\hline Total & & & & & & & \\
\hline
\end{tabular}


Esse resultado é decorrente do efeito da produção de matéria seca de $B$. brizantha do ano anterior, que foi dessecada para a semeadura do ano agrícola 2003/04; em virtude do maior espaçamento entre linhas, a forrageira se beneficiou da maior radiação incidente, proporcionando maior acúmulo de biomassa durante o primeiro ano; conseqüentemente, ao ser dessecada, o aporte de palhada sobre a superficie atuou como barreira física à emergência das plantas daninhas (Theisen et al., 2000). Efeito semelhante foi observado por Mateus et al. (2004), segundo os quais o incremento na produção de palhada propiciou controle de até $100 \%$ na emergência de plantas daninhas. De acordo com Severino et al. (2006b), o cultivo consorciado do milho com forrageiras apresenta-se como prática eficiente na supressão de plantas daninhas, por proporcionar diferentes modelos de competição e alelopatia, reduzindo, assim, o banco de sementes e a pressão de seleção sobre plantas daninhas específicas.

A dinâmica da comunidade de plantas daninhas identificadas nos anos agrícolas 2002/ 03 e 2003/04 é apresentada na Tabela 8. Com base nos resultados, observou-se que no milho solteiro a densidade das plantas daninhas aumentou no segundo ano de estudo, tanto no milho plantado a $45 \mathrm{~cm}$ quanto a $90 \mathrm{~cm}$, apresentando valores da ordem de 49,9 e 112,0\%, respectivamente. Entretanto, no milho consorciado $\operatorname{com} B$. brizantha ocorreu redução da densidade das plantas daninhas em ambos os espaçamentos utilizados, superior a 70,0\%, chegando a 100,0\% no tratamento milho + Brizantha na linha e entrelinha no espaçamento de $90 \mathrm{~cm}$.

Esse resultado é muito interessante, uma vez que ressalta o caráter conservacionista do sistema plantio direto na palha, bem como evidencia o potencial do sistema na redução da densidade da população das plantas daninhas, permitindo diminuir gradual do banco de sementes ao longo dos anos e, com isso, reduzir ou até mesmo dispensar o uso de herbicidas. Carmona (1992) e Jakelaitis et al. (2003) relatam que o plantio direto ou preparo superficial do solo resulta na concentração de sementes próximo à superficie, o que tende a acelerar o decréscimo de sementes recém-derrubadas no solo, pela indução de germinação ou pela perda de viabilidade.

Pereira \& Velini (2003) ressaltam que o sistema plantio direto pode apresentar maior eficiência no controle cultural das plantas daninhas que os de cultivo mínimo e preparo convencional, reduzindo o número total de indivíduos e a diversidade da comunidade infestante.

O cultivo consorciado do milho com $B$. brizantha na linha + entrelinha no espaçamento de $90 \mathrm{~cm}$ foi a modalidade de consorciação que proporcionou maior produção de matéria seca. Entre as espécies identificadas, houve predomínio de dicotiledôneas. Além disso, a presença de $B$. brizantha em cultivo

Tabela 8 - Dinâmica da comunidade de plantas daninhas identificadas nos anos agrícolas 2002/03 e 2003/04. Botucatu-SP

\begin{tabular}{|c|c|c|c|}
\hline \multirow{3}{*}{ Tratamento } & \multicolumn{2}{|c|}{ Densidade (planta $\mathrm{m}^{-2}$ ) } & \\
\hline & \multicolumn{2}{|c|}{ Ano Agrícola } & \\
\hline & $2002 / 03$ & $2003 / 04$ & \\
\hline \multicolumn{4}{|c|}{ Espaçamento $-45 \mathrm{~cm}$} \\
\hline Milho solteiro & 54,5 & 81,7 & Aumento (\%) 49,9 \\
\hline $\begin{array}{l}\text { Milho + Brachiaria na linha } \\
\text { Milho + Brachiaria na entrelinha } \\
\text { Milho + Brachiaria na linha e entrelinha }\end{array}$ & $\begin{array}{l}14,3 \\
10,0 \\
11,5\end{array}$ & $\begin{array}{l}0,3 \\
1,7 \\
1,0\end{array}$ & $\begin{array}{c}\text { Redução (\%) } \\
97,7 \\
83,3 \\
91,3 \\
\end{array}$ \\
\hline \multicolumn{4}{|c|}{ Espaçamento - $90 \mathrm{~cm}$} \\
\hline Milho solteiro & 29,3 & 62,0 & Aumento (\%) 112,0 \\
\hline $\begin{array}{l}\text { Milho + Brachiaria na linha } \\
\text { Milho + Brachiaria na entrelinha } \\
\text { Milho + Brachiaria na linha e entrelinha }\end{array}$ & $\begin{array}{l}3,0 \\
5,0 \\
1,5\end{array}$ & $\begin{array}{l}0,7 \\
0,3 \\
0,0\end{array}$ & Redução (\%) 77,7 \\
\hline
\end{tabular}


consorciado diminuiu a densidade de plantas daninhas. A utilização do cultivo consorciado do milho $\operatorname{com} B$. brizantha na linha+entrelinha proporcionou indice de controle de 95\%, independentemente do espaçamento utilizado.

\section{LITERATURA CITADA}

AIDAR, H.; RODRIGUES, J. A. S.; KLUTHCOUSKI, J. Uso da integração lavoura-pecuária para produção de forragem na entressafra. In: KLUTHCOUSKI, J.; STONE, L. F.; AIDAR, H. Integração lavoura-pecuária. Santo Antonio de Goiás: Embrapa Arroz e Feijão, 2003. p. 225262.

ARAÚJO, A. G.; RODRIGUES, B. N. Manejo mecânico e químico da aveia preta e sua influência sobre a taxa de decomposição e o controle de plantas daninhas em semeadura direta de milho. Planta Daninha, v. 18, n. 1, p. $151-160,2000$

BRAUN-BLANQUET, J. Fitosociologia: bases para el estudio de las comunidades vegetales. Madrid: H. Blume, 1979. $820 \mathrm{p}$.

CARMONA, R. Problemática e manejo de bancos de sementes de invasoras em solos agrícolas. Planta Daninha, v. 10, n. $1-2$, p. 5-16, 1992.

EMPRESA BRASILEIRA DE PESQUISA AGROPECUÁRIA - EMBRAPA. Sistema brasileiro de classificação dos solos. Rio de Janeiro: 1999. 412 p.

FREITAS, F. C. L. et al. Cultivo consorciado de milho para silagem com Brachiaria brizantha no sistema de plantio convencional. Planta Daninha, v. 23, n. 4, p. 635-644, 2005a.

FREITAS, F. C. L. et al. Formação de pastagem via consórcio de Brachiaria brizantha com milho para silagem no sistema de plantio direto. Planta Daninha, v. 23, n. 1, p. $49-58,2005 b$

JAKELAITIS, A. et al. Dinâmica populacional de plantas daninhas sob diferentes sistemas da manejo nas culturas de milho e feijão. Planta Daninha, v. 21, n. 1, p. 71-79, 2003.

JAKELAITIS, A. et al. Manejo de plantas daninhas no consórcio de milho com capim-braquiária (Brachiaria decumbens). Planta daninha, v. 22, n. 4, p. 553-560, 2004.

JAKELAITIS, A. et al. Influência de herbicidas e de sistemas de semeadura de Brachiaria brizantha consorciada com milho. Planta Daninha, v. 23, n. 1, p. 59-67, 2005 a.

JAKELAITIS, A. et al. Efeitos de herbicidas no consórcio de milho com Brachiaria brizantha. Planta Daninha, v. 23, n. 1 , p. $69-78,2005 b$
KISSMANN, K. G.; GROTH, D. Plantas infestantes e nocivas. 2.ed. São Paulo: BASF, 1997. Tomo I. 825 p

KISSMANN, K. G.; GROTH, D. Plantas infestantes e nocivas. 2.ed. São Paulo: BASF, 1999. Tomo II. 978 p.

KISSMANN, K. G.; GROTH, D. Plantas infestantes e nocivas. 2.ed. São Paulo: BASF, 2000. Tomo III. 726 p.

KLUTHCOUSKI, J. et al. Sistema Santa Fé - Tecnologia Embrapa: integração lavoura-pecuária pelo consórcio de culturas anuais com forrageiras, em áreas de lavoura, nos sistemas direto e convencional. Santo Antonio de Goiás, GO Embrapa Arroz e Feijão, 2000. 28 p. (Circular Técnica, 38)

MARTINS, D. Classificação climática da Fazenda Experimental Lageado. LOCAL: 2003. 1 p. (Circular Técnica).

MATEUS, G. P.; CRUSCIOL, C. A. C.; NEGRISOLI, E. Palhada do sorgo de guiné gigante no estabelecimento de plantas daninhas em área de plantio direto. Pesq. Agropec. Bras., v. 39, n. 6, p. 539-542, 2004.

MELLO, L. M. M. et al. Integração agricultura-pecuária em plantio direto: produção de forragem e resíduo de palha após pastejo. Eng. Agríc., v. 24, n. 1, p. 121-129, 2004.

MUELLER-DOMBOIS, D.; ELLENBERG, H. Aims and methods of vegetation ecology. New York: John Wiley \& Sons, 1974. 547 p.

PEREIRA, F. A. R.; VELINI, E. D. Sistemas de cultivos no cerrado e dinâmica de populações de plantas daninhas Planta Daninha, v. 21, n. 3, p. 355-363, 2003

PORTES, T. A. et al. Análise do crescimento de uma cultivar de braquiária em cultivo solteiro e consorciado com cereais Pesq. Agropec. Bras., v. 35, n. 7, p. 1349-1358, 2000.

SEVERINO, F. J.; CARVALHO, S. J. P.; CHRISTOFFOLETI, P. J. Interferências mútuas entre a cultura do milho, espécies forrageiras e plantas daninhas em um sistema de consórcio. II - implicações sobre as espécies forrageiras. Planta Daninha, v. 24, n. 1, p. 45-52, 2006a.

SEVERINO, F. J.; CARVALHO, S. J. P.; CHRISTOFFOLETI, P. J. Interferências mútuas entre a cultura do milho, espécies forrageiras e plantas daninhas em um sistema de consórcio. III - implicações sobre as plantas daninhas. Planta Daninha, v. 24, n. 1, p. 53-60, 2006 b.

THEISEN, G.; VIDAL, R. A.; FLECK, N. G. Redução da infestação de Brachiaria plantaginea em soja pela cobertura do solo com palha de aveia preta. Pesq. Agropec. Bras., v. 35, n. 4 , p. $753-756,2000$.

TREZZI, M. M.; VIDAL, R. A. Potencial de utilização de cobertura vegetal de sorgo e milheto na supressão de plantas daninhas em condições de campo: II - Efeitos da cobertura morta. Planta Daninha, v. 22, n. 1, p. 1-10, 2004. 